\title{
FLIPPED FOR CRITICAL THINKING: EVALUATING THE EFFECTIVENESS OF A NOVEL TEACHING APPROACH IN POSTGRADUATE LAW MODULES
}

\author{
Margaret Liu \\ Law School, Coventry University (United Kingdom)
}

\begin{abstract}
Flipped classroom is a novel model that can help students develop their learning skills of critical thinking in postgraduate law program. The assumption is made that the flipped classroom benefits students by fully engaging in learning experience through team working and pre-designed class activities with tailor-made questions. The literature about flipped teaching reveals that the flipped model is still underutilized and underexplored in the higher education law teaching. This study thus aims to fill in this gap by developing a model that can provide a foundation for further research and practice for flipped learning in higher legal education. This study presents information about how this model promotes greater critical thinking. The proposed research and design model is a threefold dimension. Every dimension is at the right angles to other dimensions comparing flipped classroom effective rating with: i) different communicative learning stages, ii) engaging experiences, and iii) final grade). This model was implemented in a flipped classroom environment and evaluated based on Module Evaluation Questionnaires and final module grades.

Research was conducted using eleven-week-long postgraduate law modules of "international trade law", "international human rights law" and "international criminal law". The participants in the study were 65 postgraduate students who were attending the above three law modules at Coventry University in the academic year 2017/18 and 2018/19. Data was collected from students who completed module survey in each term and submitted summative assessment for their final module grade.

Result shows that over $90 \%$ post graduate law students found the flipped classroom model to be either effective or very effective to promote critical thinking. Students who perceived effectiveness of the flipped classroom had a significant association to their academic performance in the course as measured by their final grade. However, students who found the flipped classroom to be effective were more likely to be satisfied with their learning experience with their counterparts and interaction with lecturers.
\end{abstract}

Keywords: Flipped classroom, critical thinking, learning experience, problem-solving activities and team working.

\section{Introduction}

The face of legal education is ever changing and constantly evolving. A growing body of literature suggests that recent advances in high technology is shifting the law teaching and learning into a new direction in high education. Advances in high technology have led to a number of "blended learning" (Bergmann and Sams, 2012) initiatives which combine classroom and online learning across the global and in the United Kingdom. These initiatives are now seen as playing an increasingly more influential role in the way today's law students assimilate information and learning within an educational setting. It is submitted that blended learning can help maximize lecturer efficiency, increase student engagement, enrich students learning experience, and improve retention rates. One of the applications of blended learning that has been widely recognised by scholars and practitioners (Baker, 2000; Bate et al., 2012; Lage et al., 2000) is the flipped classroom. The flipped classroom is a new pedagogical teaching and learning approach that can helps students develop their learning skills of critical thinking. The most common features of the flipped classroom involve providing instructional resources for students to use outside of the class with the aid of social media and online networking and freeing up class time for more engaging activities facilitated by lecturers.

Attitudes towards the flipped classroom differ among different authors. Supporters of the 'flipped classroom' describe it (Millard, 2012) as a creation of a video lecture, screencast, or vodcast that teaches students the concept, freeing up class time for more engaging and often collaborative activities typically facilitated by the lecturer. Miller (2012) defends flipped classroom by addressing "students prepare for class 
by watching video, listening to podcast, reading articles, or contemplating questions that access their prior knowledge." Conversely, critics claim that there were some gaps in the area of this pedagogical design, including the lack of a comprehensive research model, insufficient discussion of digital learning platforms, and lack of design guidelines for course activities (Baker, 2012: Driscoll, 2012; Fulton, 2011). Some scholars have criticised the flipped classrooms saying that "it privileges the educator's view and ignores the student's point of view" (Chen et al., 2014), other argues that the flipped classroom "lacks specifications about individual learning space (both formal and informal) and learning platform (Hamdan, et al., 2013).

Yet, none of these views identify how many dimensions/aspects should be included in a flipped classroom implementation for law teaching, and what learning skills students are expected to develop under the different dimensions. Therefore, my flipped classroom model will fill in this gap by flipping the traditional in-class lectures and contents outside of the classroom with self-directed home learning and collaborative activities, and freeing up classroom time for active learning, including group presentation/debate, tutor's clarification and knowledge application. This study aims to provide a foundation for further research and practice for flipped learning in higher education of law teaching with a threefold dimension focusing on i) different communicative learning stages, ii) engaging experiences, and iii) final grade). The principal aim of flipped classroom is to help students develop study skills of critical thinking, which will be of crucial significance for law students. The development of critical thinking could, on the one hand, hinge on students' final module grades and facilitation of their learning experience by more effectively interact with and learn from their peers. On the other hand, the lecturer was given more flexibility to cover a wide range and depth learning materials, provide in-class applied learning opportunities based on problem-solving activities and offer timely feedback and guidance to students. Yet in my study, the flipped learning approach had its fair share of challenges, which were largely dependent on the use of and management of IT technology on Moodle module website. Despite these challenges, the flipped classroom is an effective teaching approach at the postgraduate level setting for developing the skills of critical thinking.

\section{Structure and setting of the flipped classroom}

The objective of the postgraduate law flipped classroom was twofold: i) to help students develop learning skills of critical thinking and; ii) to promote student's self-responsibility for their studies by fully engaged in the learning experience. To this end, my flipped classroom was designed into two stages with four components. Two stages are in-class and outside class stages. The four components are pre-class activities, in-class activities, tutor's clarification and knowledge application with the aim to promote a positive learning environment so as to stimulate flexible learning, intentional contents, self-responsibility and team work environment. The setting of my flipped classroom emphasized a "learning cycle" (Gerstein, 2011). Students prepared for class individually by conducting out-of-class activities at home with tailored questions directed by the lecturer. In order to make meaningful connections between homework and in-class activities, students were assigned into adversary groups preparing for their presentation after individual activities. The pre-class learning pedagogy improved students' communication skills by working with their study groups conducting research and preparing for class, which provided students with opportunities to tackle and resolve problems in the topic, to identify legal issues of the case under discussion, and be able to work effectively with culturally diverse individuals. In class, students were allocated into adversary groups for group presentation and debate in order to promote their skills of critical thinking. After the students' presentation and debate, the lecturer clarified the issues relating to the subject matter under discussion to enable students to comprehend the subject matter in great depth.

My flipped classroom contained a cycle beginning with an-individual-online-case study or individual-home-video watch on the Moodle module website; followed by a period set aside to work in teams and then a session of feedback from the lecturer. The final and crucial component of my flipped classroom was the knowledge application to test the efficiency and effectiveness of learning experience. The mode to conduct such a test was to ask students to write a case note in a manner of formative assessment directly relevant to online cases or video watch. My flipped classroom served to emphasize every learning process - pre-class digital aid learning activities, in-class student-lecturer interactive activities and knowledge application.

In this pedagogical design, students researched the norms or principles of the topic they came across while studying online cases or watching online videos, and they are more competent, active and self-became motivated. To boost pre-class activities, online discussion was launched for students to share their views of the topic under discussion, and the Moodle lecturer-student communication platform was also adopted in order to answer students' enquiry timely and support those students who are confused. 
Figure 1. A typical flipped classroom showcases a learning cycle for critical thinking.

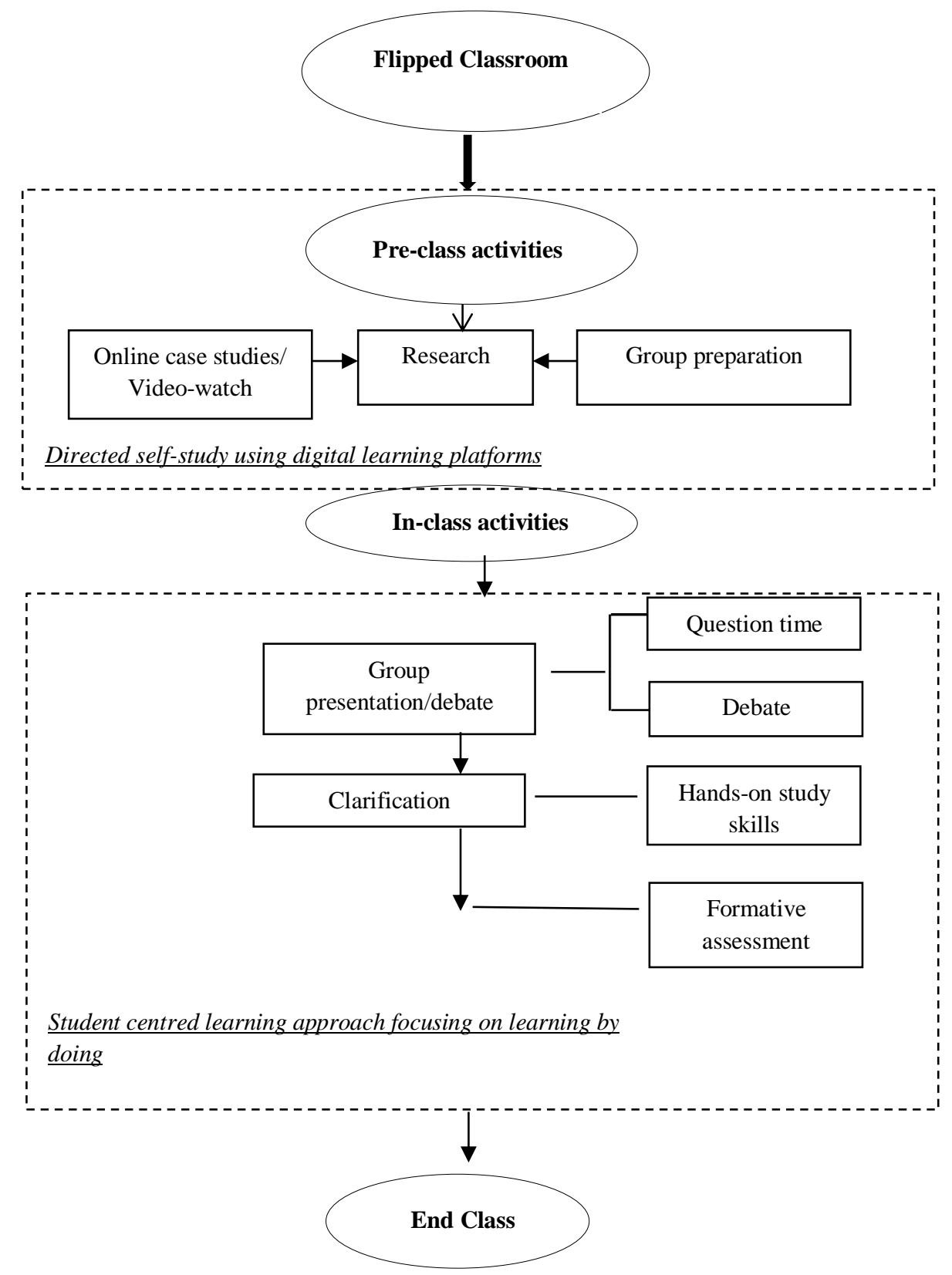

My flipped classroom excelled in the flexible learning environment, classroom culture, lecturer's steering gear and learning by doing, characterized as following:

- To support a flexible learning environment, a variety of learning modes has been launched to enable students choose where and when they learn - reading online case studies or video watching at home, in campus, on the train and so forth.

- The classroom culture shifts from a lecturer-centred learning approach to a student-centred learning approach, freeing up valuable class time for exploring topics in depth via group presentation/debate, thus creating rich learning opportunities.

- The lecturer gears in-class presentation/debate to clarification by prioritizing legal issues in order to develop students' learning skills of critical thinking.

The above components for pedagogical design facilitated "learning by doing" (Dewey, 1916) and deep learning, which computer platforms playing an important role as students participated in and evaluated to their learning using computers. The term "Learning by doing", in Jone's (Jones, et al., 2008) view, means "Learning by Networking", where students rely heavily on social media and online networking as a supplementary learning tool. Both "Learning by doing" and "Learning by networking" reflects a current trend in higher education emphasizing the activities-oriented nature of flipped learning. Students preferred the flipped classroom because of the individual learning pace and learning platforms, where students 
learned using any device, at any location, and through a multitude of competing platforms (Chen, et al., 2014). The lecturer adjusted his/her methodology to accommodate students who might be reading online cases or watching videos from different parts of the UK to promote active learning and promoted students fully engaged in the study experience.

The flipped classroom also aims to promote classroom culture. The shift from a lecturer-centred culture to a student centred culture aimed to enrich the student learning experience and keeps students alert, enthusiastic, and engaged in knowledge acquisition and construction. The student learning experience is a crucial factor for gauging whether a new learning method is successful (Teng, et al., 2012) because how students experience their education determines the effectiveness, efficiency and success of flipped learning. Therefore, keeping students alert, enthusiastic, and engaged in a flipped classroom determines the success and effectiveness of a flipped classroom.

For law teaching, critical thinking skill is a skill that lecturers should help students to develop. The critical thinking skill can be stimulated by inputs from both lecturers and students. Simply a more robust model of flipped classroom must include students and lecturers' perspectives - lecturers content planning and activity design and students contribution to their point of view of the topic through pre-designed in-class and out-of-class activities to support deep learning, thus develop critical thinking skills.

\section{Participants and data collection}

The participants in the study were 65 postgraduate law students who were attending the modules of either "international trade law" or "international criminal law" and "international human rights law" at Coventry Law School in the academic year 2017/18 and 2018/19. Data collected from students who completed Module Evaluation Questionnaires (MEQ) during the period of studying these modules and submitted summative assessment for their final module grade. MEQ surveys were administrated to students in class with an online survey code through an independent module survey team and teaching staff was required to leave the room for a 15-minute survey while students were filling in the forms of MEQ. Data collection was on the same day in class, normally in week 8 of each term. Participation in this study was voluntary with no tangible incentives provided to the students. Participant anonymity was maintained throughout the MEQ. This survey code will be returned to teaching staff after the survey team completed data analysis and teaching staff was required to provide feedback on the Moodle module website. The survey contained 22 questions in total, 20 of which were selected response range from definitely agree, mostly agree, neither disagree nor agree, mostly disagree to definitely disagree and 2 were open-ended questions.

Table 1 of Module Evaluation Questionnaires shows the survey result relevant to the questions of effective learning and learning engagement based on 65 students who completed the MEQ. The survey questions are listed on the first column, the second-to-the-sixth-column demonstrates the percentage of student's feedback on the modules, ranging from agree to disagree. The numbers in brackets are the reflection of student's agreement with the survey questions.

Table 1. Module Evaluation Questionnaires.

\begin{tabular}{|c|c|c|c|c|c|}
\hline Module Evaluation Questionnaires & $\begin{array}{l}\text { Definitely } \\
\text { agree }\end{array}$ & Most agree & $\begin{array}{l}\text { Neither } \\
\text { disagree } \\
\text { nor agree }\end{array}$ & $\begin{array}{l}\text { Most } \\
\text { disagree }\end{array}$ & $\begin{array}{l}\text { Definitely } \\
\text { disagree }\end{array}$ \\
\hline $\begin{array}{l}\text { I have had the right opportunities to work } \\
\text { with others to enhance my learning }\end{array}$ & $\begin{array}{l}50 \% \\
(33)\end{array}$ & $\begin{array}{l}37.5 \% \\
(24)\end{array}$ & $\begin{array}{l}12.5 \% \\
(8)\end{array}$ & 0 & 0 \\
\hline $\begin{array}{l}\text { CU Online is used effectively to support } \\
\text { my learning" }\end{array}$ & $\begin{array}{l}42.9 \% \\
(28)\end{array}$ & $\begin{array}{l}42.9 \% \\
(28)\end{array}$ & 0 & $\begin{array}{l}14.2 \% \\
(9)\end{array}$ & 0 \\
\hline $\begin{array}{l}\text { I have received helpful and timely } \\
\text { feedback on my work }\end{array}$ & $\begin{array}{l}37.5 \% \\
(24)\end{array}$ & $\begin{array}{l}62.5 \% \\
(41)\end{array}$ & 0 & 0 & 0 \\
\hline This module is intellectually stimulating & $\begin{array}{l}45.5 \% \\
(30)\end{array}$ & $\begin{array}{l}54.5 \% \\
(35)\end{array}$ & 0 & 0 & 0 \\
\hline $\begin{array}{l}\text { This module has provided me with } \\
\text { opportunities to apply what I have } \\
\text { learned }\end{array}$ & $\begin{array}{l}80 \% \\
(52)\end{array}$ & $\begin{array}{l}20 \% \\
(13)\end{array}$ & 0 & 0 & 0 \\
\hline $\begin{array}{l}\text { This module has challenged me to } \\
\text { achieve my best work }\end{array}$ & $\begin{array}{l}81.8 \\
(53)\end{array}$ & $\begin{array}{l}18.2 \\
(12)\end{array}$ & 0 & 0 & 0 \\
\hline $\begin{array}{l}\text { This module has prompted me to explore } \\
\text { ideas and concepts in greater depth }\end{array}$ & $\begin{array}{l}72.7 \% \\
(47)\end{array}$ & $\begin{array}{l}27.3 \% \\
(18)\end{array}$ & 0 & 0 & 0 \\
\hline $\begin{array}{l}\text { Sufficient academic advice and guidance } \\
\text { are available on this module }\end{array}$ & $\begin{array}{l}54.5 \% \\
(35)\end{array}$ & $\begin{array}{l}36.4 \% \\
(24)\end{array}$ & 0 & $\begin{array}{l}9.1 \% \\
(6)\end{array}$ & 0 \\
\hline $\begin{array}{l}\text { Moodle and/or other online learning } \\
\text { environments are used effectively to } \\
\text { support my learning }\end{array}$ & $\begin{array}{l}54.5 \% \\
(35)\end{array}$ & $\begin{array}{l}36.4 \% \\
(24)\end{array}$ & 0 & $\begin{array}{l}9.1 \% \\
(6)\end{array}$ & 0 \\
\hline
\end{tabular}




\section{Assessment of the modules}

At the beginning of each term, a module guide of course syllabus was provided to students that concisely introduced them to the nuances of the flipped classroom while clearly articulating the assessment aspects for the module. In this study, the flipped classroom used both formative and summative assessment of students' learning.

The formative assessment was predominantly centred on in-class assessment as articulated in the preceding section. The in-class formative assessment permitted students to be purposively engaged in their own learning by consulting lecture notes, books, statutes and cases while it enabled the tutor to provide real-time guidance, and as appropriate fill in the students' gap in knowledge. The formative assessment was composed of one title for students to write on. The priority concern of formative assessment is to provide feedback to students to enable them to write a high quality coursework for summative assessment. The summative assessment was consisted of two topics for students to choose: one is an essay and the other one is a case study, which assessed the students' ability to critically read, extract, footnote and analyse information and encouraged students to use higher critical thinking and reasoning skills that reflected the learning outcomes and skills of the modules. The blending of both summative and formative is good to develop reflective practice in our students and encourage them to revisit completed work for their further development. Students make progress dramatically from failed in their formative assessment up to around 50/60 marks, some students achieve a mark up to 70 marks in their summative assessment for the modules.

Undoubtedly, the flipped classroom brings student's different learning styles into play and improves their study skills of critical thinking and self-responsibility for their studies as they participate in and evaluate their learning. Moreover, formative and summative assessment demonstrated that student learning outcomes are improving year by year in the past two years.

\section{References}

Baker, J. W. (2000). The "Classroom Flipped": Using Web Course Management Tools to Become the Guide by the Side. Proceedings of the11th International Conference on College Teaching and Learning, Jacksonville, Florida, United States.

Baker, C. (2012). Flipped Classroom: Turning Learning Upside Down. Deseret News. Available at http://www.deseretnews.com/article/765616415/Flipped-classroom-turning-learning-upsidedown.html?pg=all.

Bergmann J. \& Sams, A. (2012). Flip Your Classroom: Reach Every Student in Every Class Every Day. Washington, DC: Internal Society for Technology in Education.

Chen, Y., Wang, Y., Kinshuk \& Chen, N. (2014). Is Flipped Enough? Or should we use the FLIPPED model instead?. Computer \& Education 79 (2014), pp. 16-27.

Dewey, J. (1916). Democracy and Education. Toledo, OH: Student Handouts, Inc.

Jones, C. R., Ferreday, D., \& Hodgson, V. (2008). Networked Learning a Relational Approach: Weak and Strong Ties. Journal of Computer Assisted Learning 24(2), pp. 90-102.

Teng, D. C. E. Chen, N. S., Kinshuk, S. \& Leo, T. (2012). Exploring Students' Learning Experience in an International Online Research Seminar in the Synchronous Cyber Classroom. Computer \& Education 58, pp. 918-930.

Moore, M. G. (1993). Theory of Transactional Distance. In D. Keegan (Ed.) Theoretical Principles of Distance education. New York: Routledge.

Millard, E. (2012). 5 Reasons Flipped Classroom Work: Turning Lectures into Homework to Boost Student Engagement and Increase Technology-fueled Creativity. University Business.com, 26-26. Available at http://www.universitybusiness.com/articles/5-reasons-flipped-classrooms-work.

Miller, A. (2012). Five Best Practices for the Flipped Classroom. Available at http://www.edutopia.org/blog/flipped-classroom-best-practices-andrew-miller.

Ryder, M. (2006). Instructional Design Models. Retrieved from the School of Education, University of Colorado Denver website http://carbon.ucdenver.edu/-mryder/itc/idmodels.html 